\title{
Variabilidad de la temperatura superficial del mar obtenida a partir de imágenes AVHRR y su relación con las pesquerías de langosta (Panulirus argus) en las aguas Cubanas (1997-2004)
}

\author{
(doi:10.4136/ambi-agua.2)
}

\author{
Regla Duthit Somoza $^{1,2}$; Milton Kampel ${ }^{2}$; Ronald Buss Souza ${ }^{2}$; Susana Cobas ${ }^{1}$ \\ ${ }^{1}$ Centro de Investigaciones Pesqueras - 5ta Ave, 246, Barlovento, Sta. Fe, Playa, Ciudad Habana, Cuba \\ E-mail: duthit@gmail.com; susana@cip.telemar.cu \\ ${ }^{2}$ Instituto Nacional de Pesquisas Espaciais - INPE, Caixa Postal 515, São José dos Campos-SP, Brasil \\ E-mail: \{milton,ronald\}@dsr.inpe.br
}

\section{RESUMEN}

Se obtiene la variabilidad espacial y temporal de la temperatura superficial del mar (TSM) para las aguas de la plataforma cubana, así como la relación de estas con las capturas de langostas, en el período comprendido entre Enero/1997-Diciembre/2004. Los datos de de esta variable ambiental son obtenidos del sensor "Advanced Very High Resolution Radiometer” (AVHRR). La periodicidad de las imágenes y de los datos de captura por zonas de pesca es mensual. Las aguas oceánicas y de la plataforma tienen un comportamiento estacional para la TSM, alcanzando las máximas en Agosto $\left(29,5^{\circ} \mathrm{C}\right)$ y las mínimas en Febrero $\left(26^{\circ} \mathrm{C}\right)$. Los valores extremos registrados se datan en Agosto del 1998 con anomalías de $1,9^{\circ} \mathrm{C}$ y de $-0,9^{\circ} \mathrm{C}$ en Febrero del 2001 . Durante el período invernal (Nov-Abr) es posible encontrar un patrón general de circulación de las aguas para el área mediante la observación de las imágenes; en verano (May-Oct) no se observa. Se obtiene una baja correlación entre las anomalías de TSM y las capturas de langostas por zonas de pesca. Los mejores coeficientes de correlación $(0,48)$ se hallaron para la zona occidental de la isla, con 4 años de desfase.

Palabras claves: temperatura superficial del mar; AVHRR; langostas; anomalías.

\section{Variabilidade da temperatura superficial do mar obtida a partir de imagens AVHRR e sua relação com a pesca de lagosta (Panulirus argus) em águas Cubanas (1997-2004)}

\section{RESUMO}

Foi obtida a variabilidade espacial e temporal da temperatura superficial do mar (TSM) para as águas da plataforma cubana, assim como a relação destas com as capturas de lagosta, no período compreendido entre janeiro/1997 e dezembro/2004. Os dados de TSM foram obtidos do sensor "Advanced Very High Resolution Radiometer" (AVHRR). A periodicidade das imagens foi mensal, da mesma forma que a regularidade dos dados de captura por zonas de pesca. As águas oceânicas e da plataforma têm um comportamento sazonal para a TSM, alcançando as máximas em agosto $\left(29,5^{\circ} \mathrm{C}\right)$ e mínimas em fevereiro $\left(26^{\circ} \mathrm{C}\right)$. Os valores extremos registrados ocorreram em agosto de 1998 , com anomalias de $1,92^{\circ} \mathrm{C}$ e de $-0,88^{\circ} \mathrm{C}$ em fevereiro de 2001. Durante o inverno (nov - abr) é possível encontrar um padrão geral de circulação das águas mediante a observação das imagens; já no verão (mai - out) não se nota. Foi obtida uma baixa correlação entre as anomalias de TSM e as capturas de lagosta por zonas de pesca. Os melhores coeficientes de correlação $(0,48)$ foram encontrados na zona ocidental da ilha com 4 anos de fase.

Palavras-chave: temperatura superficial do mar; AVHRR; lagostas; anomalias. 


\section{INTRODUCCIÓN}

El alcance de las ciencias pesqueras y los componentes relacionados con la biología marina, ha sido definido tradicionalmente por la escala de las pesquerías estudiadas, la cual puede oscilar desde unos pocos kilómetros cuadrados (ejemplo: en el caso de las pesquerías de invertebrados) a cientos de kilómetros cuadrados en el caso de las pesquerías de altura. Por ello se plantea, que el manejo de las pesquerías debe documentarse con mapas de los “ecosistemas bases” que incluya en esencia sus procesos ecológicos relevantes (Pauly et al., 2001).

Las pesquerías de langosta espinosa (Panulirus argus) son realizadas en los mares poco profundos de la plataforma cubana los que constituyen el hábitat natural de esta especie, que por su elevado valor económico es reconocido como el principal recurso pesquero del país. La relación de variables abióticas o ambientales con la biología y pesquería de esta especie es un asunto abordado por varios autores desde el siglo pasado, al respecto Gómez (1980) establece una relación entre la temperatura del aire en Batabanó y el inicio de la maduración de las hembras en la zona, existiendo la posibilidad de predecir la fecha de ocurrencia del pico de maduración de langosta en esta zona. Otro aspecto es el referido a la migraciones masivas de langosta en el período octubre -diciembre (migración otoñal), donde un conjunto de autores han dedicado sus estudios. Entre ellos podemos mencionar Baisre et al. (1984), Hernández (1988), García et al., (1991), Hernández et al. (1995), Hernández y Puga (1995), los cuales realizaron un análisis considerando las posibles causas de este comportamiento, relacionándolo con estímulos de origen hidrodinámicos como posible causas, entre los que se citan la entrada al país de los llamados frentes fríos y los ciclones tropicales. También, Hernandez (2002), estudió teleconexiones de fenómenos que tienen impacto a escala Global como el ENOS (El Niño Oscilación- Sur) con las variabilidades de la temperatura en las aguas cubanas así como la influencia de las anomalías de TSM sobre el desove y reclutamiento de la langosta espinosa Panulirus argus en la plataforma cubana, obteniendo todas las correlaciones con alto nivel de significación estadística pero con meses de desfase para el Golfo de Batabanó.

Los patrones espaciales y temporales de variación de la temperatura superficial del mar (TSM) juegan un papel fundamental en la determinación de las condiciones para la supervivencia de los organismos que habitan en las aguas poco profundas, pues reflejan los rangos de ocurrencia de los procesos que allí tienen lugar. El estudio de estas propiedades básicas del océano podría ayudarnos a un mejor entendimiento de los ecosistemas oceánicos y costeros, así como de los procesos bióticos y abióticos que ocurren en estas aguas. Hoy en día, la adquisición de datos oceanográficos convencionales sinópticos sobre grandes áreas y por largos períodos de tiempo aun es extremadamente difícil y cara, en comparación a los datos de satélite. Los datos obtenidos por sensores orbitales con visión sinóptica convencional y con grandes resoluciones espaciales pueden proveer series temporales de datos de alta frecuencia por largos periodos de tiempo (Robinson, 1985, 2004).

El desarrollo del sensoramiento remoto para aplicaciones pesqueras impone el uso de esta tecnología para la obtención de datos ambientales que pudieran ser relacionados con la explotación de la langosta espinosa en aguas cubanas, en el área de estudio seleccionada, no existen antecedentes del uso de está importante herramienta en el análisis de las interacciones de variables ambientales con las pesquerías.

Según Souza (2005), las ventajas de utilizar datos de sensoramiento remoto para la obtención de variables ambientales está, en que la elevada sensibilidad de los sensores actualmente en operación permite captar pequeñas variaciones en áreas considerablemente mayores, comparada con los resultados alcanzados por estudios realizados a bordo de 
embarcaciones. Teniendo en cuenta la disponibilidad de las imágenes del sensor AVHRR (Advanced Very High Resolution Radiometer) de la serie NOAA (Nacional Oceanographic and Atmospheric Administration) de los Estados Unidos para TSM (Temperatura Superficial del Mar), así como el cúmulo de datos que de estas puede ser obtenido nos planteamos el objetivo siguiente:

Describir la variabilidad de la TSM obtenida a partir del sensor AVHRR en aguas oceánicas adyacentes a la plataforma cubana y la relación de esta variable ambiental con las capturas de langostas en zonas de pesca; período comprendido entre enero de 1997 y diciembre del 2004.

\section{MATERIALES Y MÉTODOS}

\section{1. Área de estudio}

La selección del área de estudio (Figura. 1) se realizó teniendo en cuenta el esquema de distribución espacial de las langostas $P$. argus durante las distintas fases de su ciclo de vida de Cruz et al. (1990), así como lo planteado por la Comisión de Pesca para el Atlántico Centro Occidental (COPACO), referente a que "los recursos de la langosta espinosa del Caribe en la región podrían estar interconectados a través del régimen de circulación de las aguas teniendo en cuenta su fase oceánica dentro del ciclo de vida” (FAO, 2003). Esta zona de estudio permite una visión general de lo que ocurre con las variables ambientales donde se desarrolla esta especie, un poco más allá de las aguas de la plataforma donde se realizan sus pesquerías.

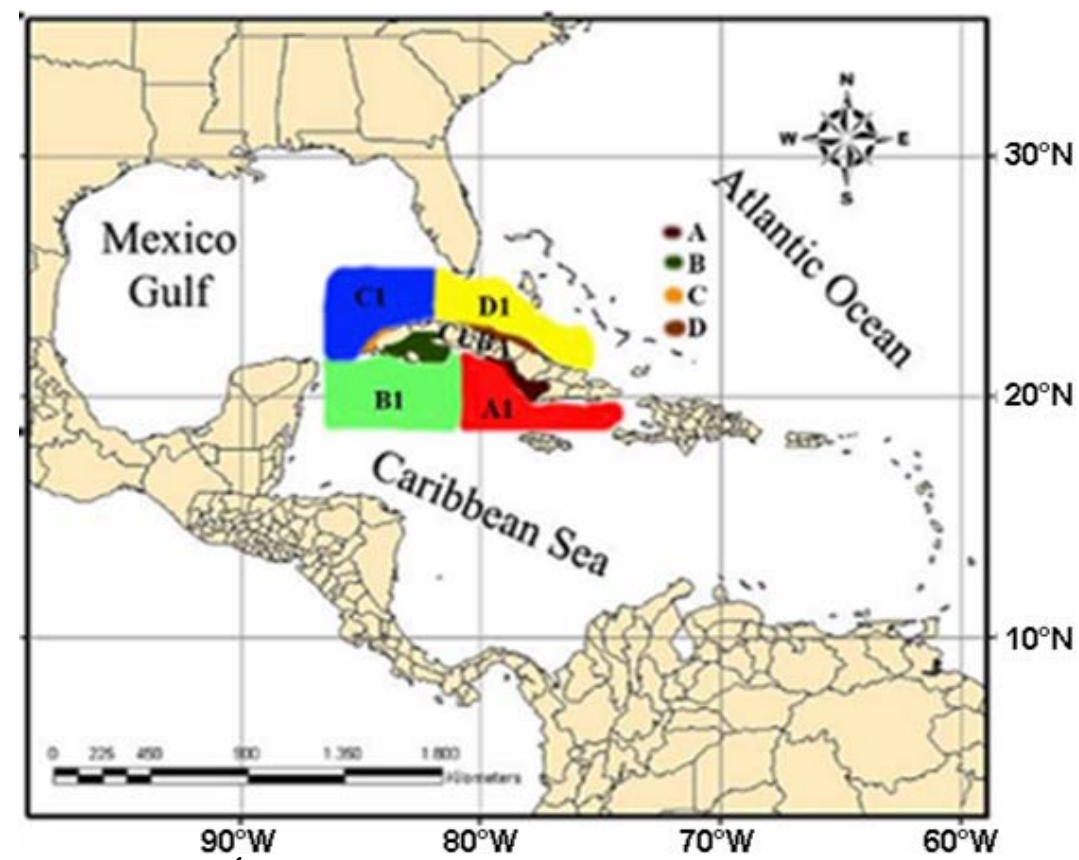

Figura. 1 Área de estudio y Zonas de Pesca; Zona A: Golfo Ana María Guacanayabo (18328,8 km²); Zona B: Golfo de Batabanó (21851,2 km²); Zona C: Archipiélago de las Coloradas (3432,5 $\left.\mathrm{km}^{2}\right)$; Zona D: Archipiélago SabanaCamagüey $\left(10739,8 \mathrm{~km}^{2}\right)$ Zonas A1, B1, C1 y D1 corresponden a las aguas adyacentes a estas regiones.

Se encuentra situada en la zona climática tropical de la Región del Caribe, sub-región 1; entre los $18-25^{\circ} \mathrm{N}$ y los $87-73^{\circ} \mathrm{W}$. Recibe una insolación anual de más de 25000 horas de luz 
en el año, la presión atmosférica es de $1017 \mathrm{hPa}$. La temperatura media del aire en el invierno entre $20^{\circ}$ y $22^{\circ} \mathrm{C}$, mientras en verano es de $26^{\circ} \mathrm{C}$ y más. El régimen de lluvia (mayo-octubre) es de más de $1200 \mathrm{~mm}$ y en período de seca (noviembre-abril) oscila entre 200 y $300 \mathrm{~mm}$ (IGACC; ICGC, 1989).

En aguas de la plataforma insular la batimetría es característica de aguas poco profundas que tienen una media para la región occidental y nor-oriental (Figura. 1 Zonas B, C, D) de 7 metros de profundidad, aproximadamente y para la región sur oriental las profundidades son mayores oscilando de 15-25 metros. Por otro lado, las zonas donde la línea de costa no es bañada por las aguas someras de la plataforma insular las profundidades aumentan bruscamente a pocos kilómetros de la costa, por lo que para las Zonas A1, B1, C1 y D1 las profundidades oscilan entre 500-5500m.

\subsection{Datos de las pesquerías de langosta en aguas de la plataforma cubana}

Se obtienen a través de la Empresa PESCACUBA, perteneciente al Ministerio de la Industria Pesquera cubana y se constituyen de las series de captura mensual nacional por zonas de pesca, para el período 1997-2004. Las zonas de pesca se obtienen del Atlas Biológico-Pesquero de Langosta (Cruz et al., 1990). Son calculadas las anomalías de la serie a partir de la media mensual de cada año y media mensual climatológica.

\subsection{Datos de TSM}

Son utilizadas las imágenes de TSM, obtenidas por el sensor AVHRR/ NOAA. Estas se logran a través de la ULR: http://podaac.jpl.nasa.gov/products/product216.html.

El producto utilizado es: "AVHRR Oceans Pathfinder Global 4 km equal-angle all SST v5 (NOAA, NASA)”. La disponibilidad de estos datos es en formato HDF en la escala global, con nivel 3 de procesamiento. Las resoluciones espaciales y temporales son de $4 \mathrm{x} 4 \mathrm{~km}$ y mensual respectivamente. Para el período de estudio entre1997-2004 fueron analizadas 96 imágenes mensuales.

Para estimar la TSM a partir del producto "Pathfinder" del sensor AVHRR es usado el algoritmo de corrección no-linear versión 4,1, aprobado para el tratamiento de datos históricos AVHRR, porque tiende a disminuir ampliamente todas las condiciones atmosféricas que interfieren en la obtención de datos. Referencias detalladas sobre el algoritmo usado para estimar la TSM para el producto "pathfinder" v5 debe consultarse a Vázquez et al. (1998).

\subsection{Procesamiento de las imágenes}

Luego de tener las imágenes globales de las medias mensuales correspondientes a la serie temporal 1997-2004 y la climatología de la TSM en un período que abarca los años 19852004, estas fueron cortadas para el área de estudio usando el software MATLAB ${ }^{(R)}$. Las imágenes obtenidas tienen 755 líneas y 386 columnas, con los datos de TSM por píxel. Cada imagen fue guardada con extensión ASCII para su posterior manipulación en ENVI 4.2 ${ }^{(\mathrm{R})}$, donde fueron geo-procesadas.

En las imágenes originales el valor de los píxeles que corresponden a la tierra muestra un valor de $-3^{\circ} \mathrm{C}$. Así fue posible descartar estos, pero aún en la obtención de los valores extremos de las imágenes se observaron valores mínimos absurdos muy lejanos a los registrados en la zona de estudio, esto fue debido a la presencia de píxeles contaminados por nubes y sombras. Conociendo que los valores de exactitud nominal del producto pathfinderTSM varía en el rango contenido entre 0,3-1 ${ }^{\circ} \mathrm{C}$ (Brown et al., 1985; Minnet, 1991), fueron tomados en cuenta los valores históricos registrados para el área y se realiza una filtración de 
estos píxeles, para que no sean tomados en cuenta en la obtención de las estadísticas básicas, por tanto se crea una mascara en IDL ${ }^{(\mathrm{R})}$ para valores inferiores a $20^{\circ} \mathrm{C}$.

Teniendo en cuenta el comportamiento de la TSM para la climatología de la zona se determinan las regiones de interés para su estudio detallado, las cuales se ubican como aparece en la Figura 1. Estas regiones delimitan las zonas de pesca de la langosta Zona A: Golfo Ana María Guacanayabo (18328,8 km²); Zona B: Golfo de Batabanó (21851,2 km²); Zona C: Archipiélago de las Coloradas (3432,5 km²); Zona D: Archipiélago SabanaCamagüey (10739,8 km²); así como las aguas oceánicas adyacentes a estas teniendo en cuenta que para el ciclo de vida de la especie en el espacio, ella desarrolla toda su fase larval en estas aguas oceánicas. Para cada una de estas áreas son determinados los valores extremos con las estadísticas básicas.

Las anomalías son comparadas con el Î́ndice Multivariado de "El Niño - Oscilación Sur (ENOS)” (MEI). Este índice considera seis variables observadas sobre la región del Pacífico Ecuatorial, las cuales son: TSM, presión al nivel del mar, componente zonal y meridional del viento en la superficie del mar, temperatura del aire en la superficie y cobertura de nubes. El índice fue obtenido para el período de 1950 a 2006 y cada valor corresponde a estaciones bimensuales (Dic/Ene, Ene/Feb...Nov/Dic). Los valores positivos representan la ocurrencia del fenómeno El Niño, mientras que los negativos corresponden a La Niña. En el presente trabajo solo son graficados los valores de la ATSM de la serie 1997-2004, además son comparados visualmente con las ATSM calculadas para el área de estudio en igual período.

\subsection{Correlaciones con las pesquerías}

Fueron realizadas a partir de las matrices conformadas por las anomalías de las medias mensuales de la ATSM por Zona de pesca y las anomalías de las capturas para la zona de pesca adyacente. Fueron calculadas para toda la serie y con desfase de 1 a 5 años. Los meses de veda (Marzo-Mayo) se eliminaron de las matrices, pues durante este período no existe variabilidad natural de la pesquería.

\section{RESULTADOS Y DISCUSIÓN}

\subsection{Climatología TSM}

Las imágenes de climatología (Figura 2) muestran estacionalidad bien definida por dos patrones de comportamiento de la TSM, para el área. De esta forma se pueden agrupar seis meses de invierno (Noviembre-Abril) y el resto de verano (Mayo-Octubre). Durante el verano no se define el régimen de circulación de las aguas descrito por Gyory et al. (2004) para el área, teniendo en cuenta los valores de TSM, mientras que para el período invernal puede apreciarse la dinámica de las aguas a través de los frentes térmicos formados en los límites de la circulación.

En las cercanías de América del Sur la TSM aumenta de sur a norte y de este a oeste, en concordancia con el movimiento de la circulación de la Corriente del Caribe. Las temperaturas más altas del área son registradas de junio-octubre en el área central del Caribe, hacia la costa sur-occidental de Cuba. Para el Golfo de México se tiene que durante el verano es observada alta homogeneidad en los valores más de $28^{\circ} \mathrm{C}$, mientras que durante el invierno se observa frente térmico provocado por la Corriente del Lazo "Loop current", que se localiza en esta área. Por otro lado tenemos que la corriente de Yucatán que se localiza al norte de la península con el mismo nombre no se destaca a través de la TSM para el área estudiada durante ninguna época del año. Para las aguas al norte de Cuba se aprecia una 


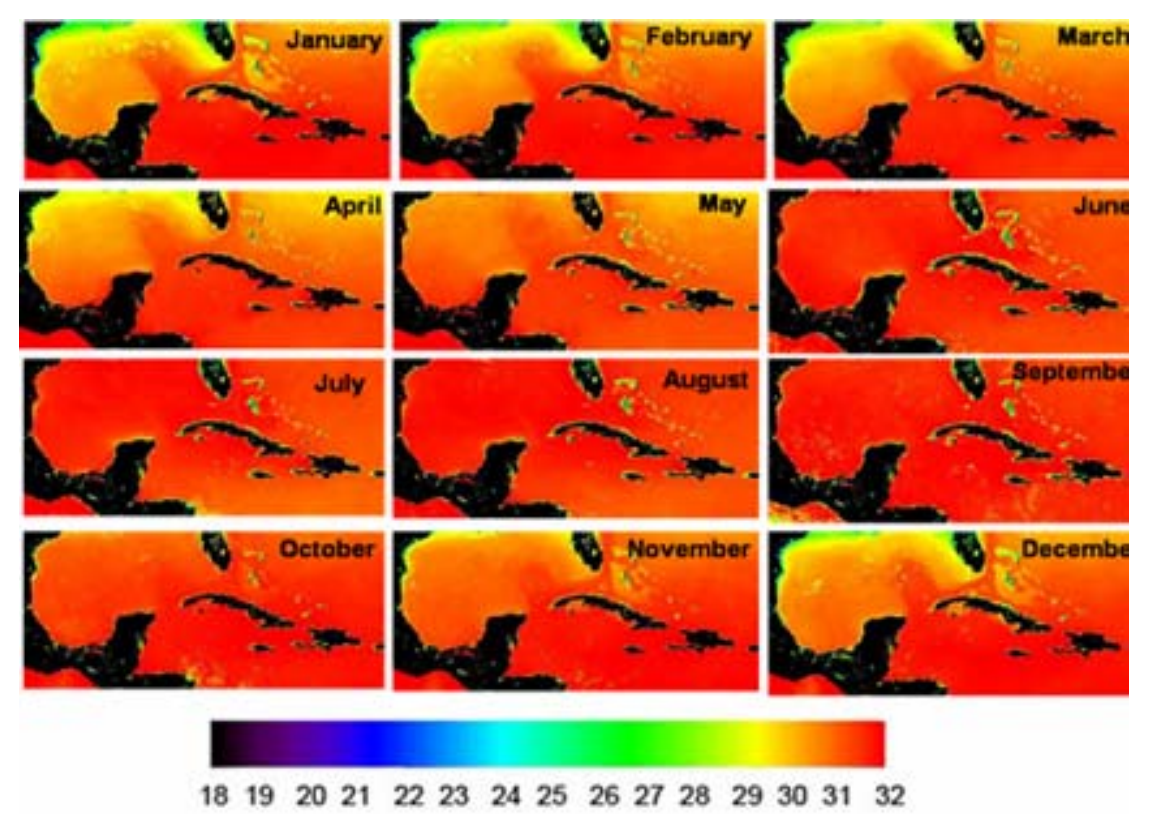

Figura 2. Imágenes AVHRR con la climatología de la Temperatura Superficial del Mar en el área de estudio para el período Enero, 1997 Diciembre, 2004.

lengua de agua caliente durante el invierno, la cual se extiende por el este de la península de la Florida hacia el norte, conformando la localización de esta corriente. Este patrón de circulación de las aguas promueve una salida sin retorno de las larvas siguiendo el régimen de la corriente de la Florida como plantea Alfonso et al. (1999). Por otro lado no es posible observar en ninguna época del año, a partir de las imágenes climatológicas, los giros existentes al sur de la plataforma cubana, descritos en la literatura por Garcia et al. (1991).

\subsection{Variabilidad de la TSM y las capturas para las zonas de pesca}

Como se aprecia en la Figura 3 al obtener las estadísticas básicas de la TSM para estas zonas de pesca se observa una marcada estacionalidad, tanto en aguas de la plataforma como en las oceánicas adyacentes.

También se aprecia un período de aguas más frías entre los meses de Noviembre-Abril con mínimos medios de $26^{\circ} \mathrm{C}$ en el mes de enero. Valores inferiores para las aguas de la plataforma $\left(25,2^{\circ} \mathrm{C}\right)$. Por otro lado se observa una elevación de la TSM entre los meses de Mayo-Octubre, con una media de máximas $\left(29,5^{\circ} \mathrm{C}\right)$ registradas para el mes de agosto también con valores extremos $\left(31,1^{\circ} \mathrm{C}\right)$ muy marcados para la plataforma. En las zonas al sur de la isla podemos observar un comportamiento planteado por Warrior et al. (2002), el cual describe que las regiones de la plataforma se enfrían más rápidamente que las aguas oceánicas, por la acción del calor sensible y las perdidas por evaporación, debido a la rápida mixtura entre las aguas de superficie y fondo en las bajas profundidades, enfriando toda la columna de agua, así como se calientan con mayor rapidez en el verano. En la Figura 3 se determina un mes de inflexión para este comportamiento en primavera y otro en otoño, para las Zonas A- A1 y B-B1 en los meses de Abril y Octubre. En cuanto a la estacionalidad anual de las capturas (Figura 4) podemos apreciar que existen dos máximos bien determinados, uno en la época de levante de veda (Junio-Septiembre) en el mes de Junio y otro menor en octubre 

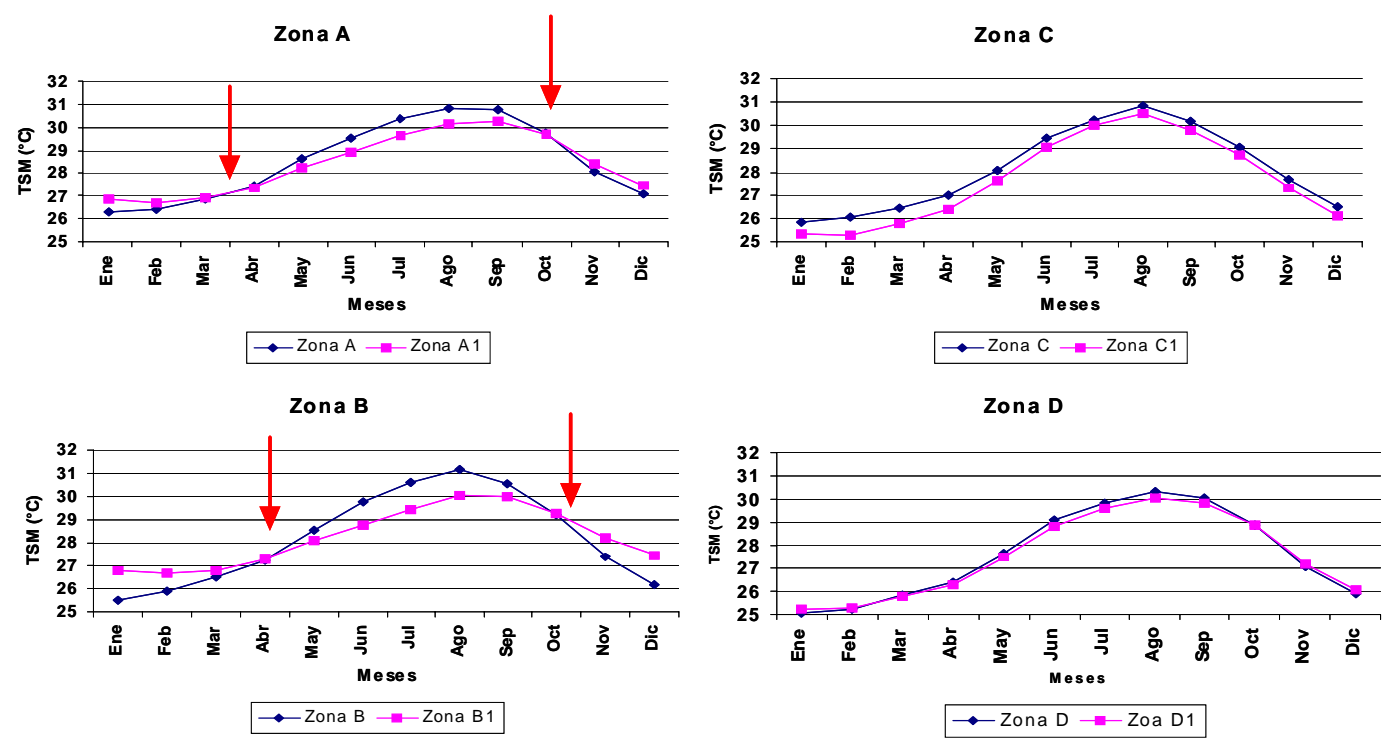

Figura 3. Estacionalidad anual de la TSM por zonas de pesca. Las zetas demarcan los meses de inflexión de la TSM entre plataforma y océano.

cuando comienza la temporada de recalo (Octubre-Febrero). Cruz et al. (1990) platea que los máximos que acontecen en las capturas al levante de veda se deben al régimen de las pesquerías con el ordenamiento pesquero del país, pues permanecen casi nulas durante un período de 110 días para proteger la reproducción, el crecimiento de los animales y la incorporación de reclutas a la pesquería. Mientras que el segundo pico de máximas registrado en la época de recalo según Baisre (2000) se debe a que el desplazamiento de las aguas superficiales de la plataforma, por la acción continuada de los vientos intensos soplados desde el Este durante la ocurrencia de eventos meteorológicos severos como lo constituyen los frentes fríos intensos, los cuales podrían provocar la entrada de aguas más profundas y frías por la zona del talud y este sería un mecanismo de disparo de las migraciones masivas de langosta en dirección a la costa en época de invierno.

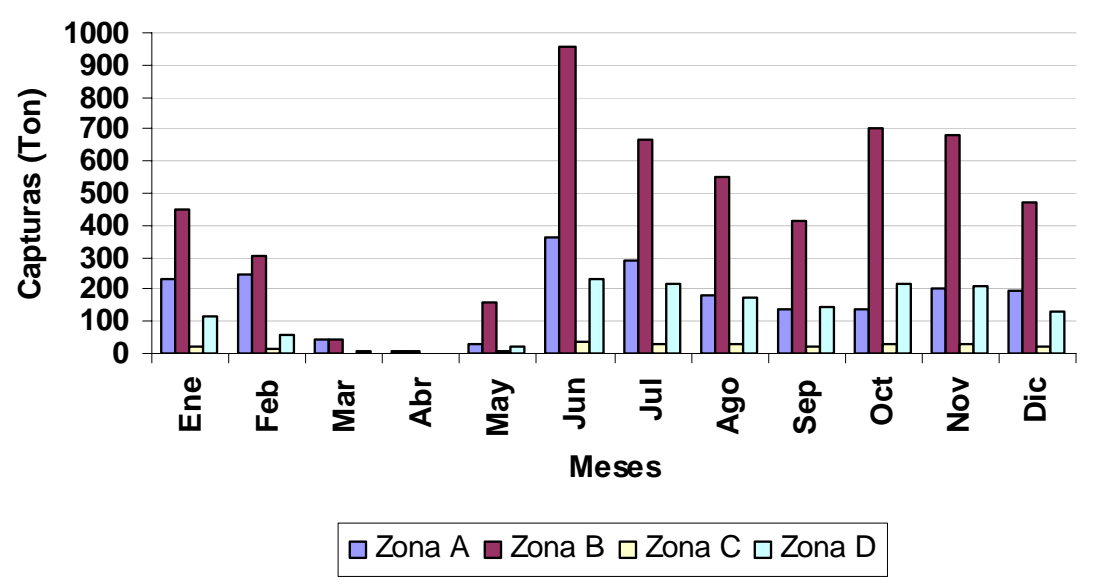

Figura 4. Estacionalidad de las capturas por zonas de pesca. (Zona A: Golfo Ana María Guacanayabo; Zona B: Golfo de Batabanó; Zona C: Archipiélago de las Coloradas; Zona D: Archipiélago Sabana-Camagüey).

Por otro lado la Figura 5 muestra que las mayores capturas promedios se obtienen en la zona Sur occidental de la isla (Zona B: $21851,2 \mathrm{~km}^{2}$ ) donde existe un mayor área de pesca, 
varios autores denominaron esta zona como la de mayor productividad del país debido a su alta disponibilidad de alimentos y refugios así como por sus condiciones ambientales Cruz et al.; (1990, 1995), Baisre y Cruz (1994), Baisre et al. (1984) y Baisre (2000) entre otros. Mientras que los menores valores se registran para la zona Nor-occidental (Zona C: 3432,5 $\mathrm{km}^{2}$ ), que tiene menor extensión. Baisre y Cruz (1994) también plantearon que esta distribución de las capturas se relaciona con la extensión de las zonas de pesca, las profundidades promedios, los tipos de artes de pesca utilizados, la disponibilidad de hábitat y alimento.

\subsection{Variabilidad de la ATSM y las capturas para las zonas de pesca}

Para toda el área existe un patrón similar de calentamiento durante el verano y enfriamiento durante el período invernal (Figura 5). En el Sur de la isla, las aguas de la plataforma son más cálidas que las oceánicas durante el verano y más frías durante el invierno, en el Norte se observan ligeramente más cálidas las aguas de la plataforma respecto a las oceánicas adyacentes para cualquier época del año. Este patrón de comportamiento podría estar relacionado con las profundidades medias de estas masas de agua que para la plataforma podría considerarse como razas con valores de $7 \mathrm{~m}$ para las zonas B, C y D y de 15 m para la A, así como con la extensión de la zona de la plataforma que es significativo con el consecuente aporte del escurrimiento terrígeno.

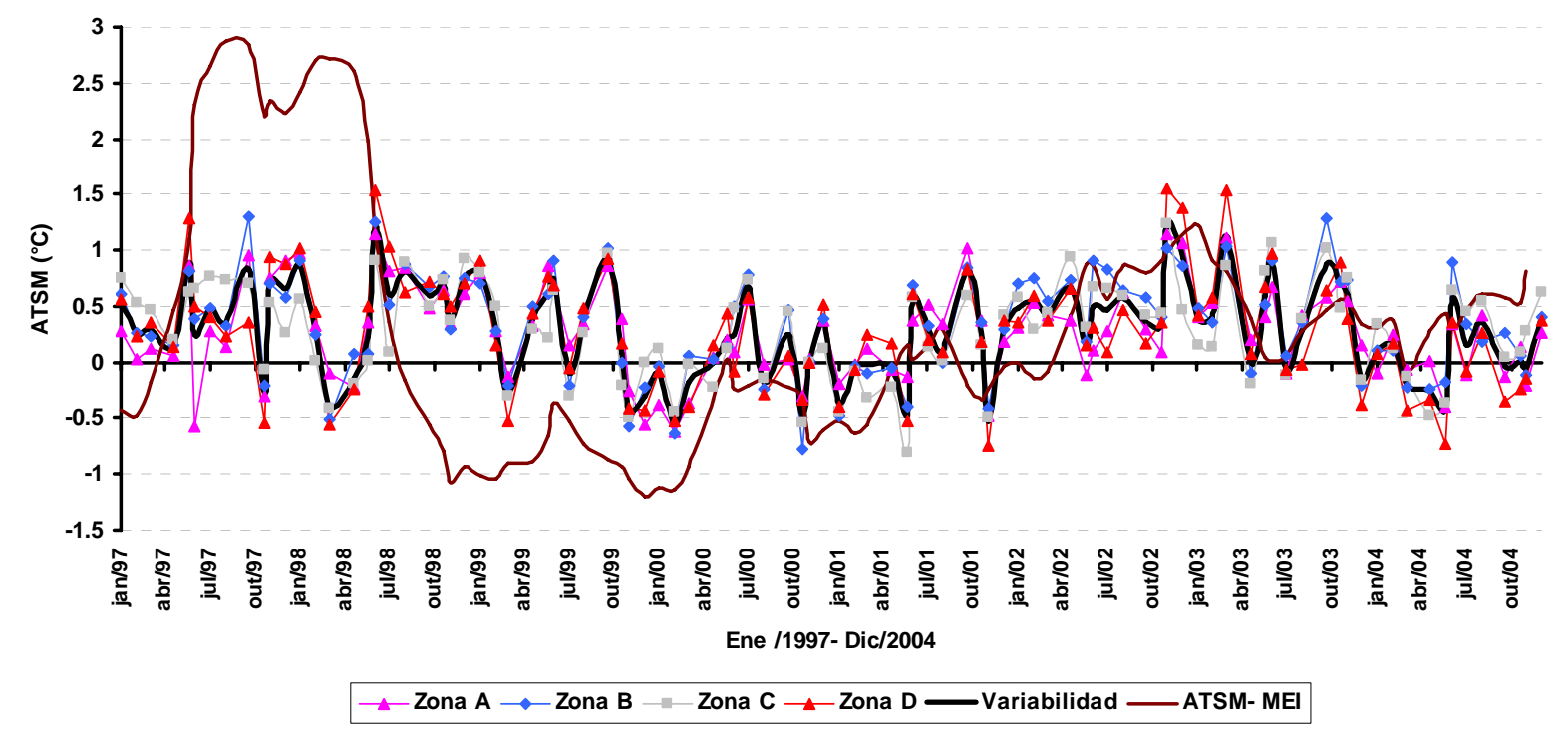

Figura 5. a) Anomalías de la TSM por zonas de pesca y anomalías globales del MEI en la serie de ATSM, serie 1997-2004. (Zona A: Golfo Ana María Guacanayabo; Zona B: Golfo de Batabanó; Zona C: Archipiélago de las Coloradas; Zona D: Archipiélago Sabana-Camagüey).

Las aguas ligeramente más cálidas que se observan para la plataforma en la zona D podrían estar relacionadas con la dinámica entre plataforma y océano, ya que el Norte de la Isla tiene menos comunicación entre estas aguas y según lo descrito por Perez-Santos (2006) existe gran número de islotes y presencia de bahías semi-cerradas que limitan el intercambio. La TSM en las aguas adyacentes a la plataforma para el sur de la isla es más alta que al norte tanto en invierno como en verano, siendo notablemente más calida para la zona sur occidental del país (Zona B1). (Cerdeira-Estrada et al., 2005).

De manera general las anomalías para el área de estudio muestran variaciones, máximas positivas de la TSM en los meses de agosto-septiembre de estos años y negativas para los meses de enero-febrero, respecto a la media climatológica de la TSM (Figura 6). Tienen un 
comportamiento similar para todas las regiones tanto de la plataforma como de las aguas adyacentes con un coeficiente de correlación de 0,9 entre estas masas de agua. Las mínimas ATSM se observaron en el invierno del 2001 (mes de Febrero, $-0,9^{\circ} \mathrm{C}$ ), mientras que las máximas se registran en el verano del 1998 (mes de Agosto, 1,9 ${ }^{\circ} \mathrm{C}$ ).

Este comportamiento para las anomalías de TSM justamente describen lo planteado por Hernández (2002); quien apunta que para los últimos eventos ENOS las altas temperaturas del mar en el Pacífico ecuatorial se reflejaron también en aguas de Cuba, pero con menor intensidad y se correlacionaron significativamente con la región de el Niño 3, que se localiza en el pacífico ecuatorial, con 5-6 meses de desfase para el Golfo de Batabanó. En la Tabla 1, se observa que podría extrapolarse lo planteado por este autor en un área específica de la plataforma al comportamiento de las ATSM en las áreas de pesca restantes debido al alto coeficiente de correlación calculado entre ellas, teniendo en cuenta al realizar este raciocinio que la Zona C es la que menos se correlaciona con el Golfo de Batabanó.

Tabla 1. Coeficientes de correlación entre las ATSM de las áreas de pesca..

\begin{tabular}{|l|r|r|r|r|}
\hline $\begin{array}{c}\text { Coeficiente } \\
\text { de } \\
\text { Correlación }\end{array}$ & Zona A & Zona B & Zona C & Zona D \\
\hline Zona A & 1 & 0.80 & 0.64 & 0.87 \\
\hline Zona B & & 1 & 0.89 & 0.82 \\
\hline Zona C & & & 1 & 0.75 \\
\hline Zona D & & & & 1 \\
\hline
\end{tabular}

La Figura 6 muestra las anomalías de las pesquerías de langosta para las cuatro zonas de pesca. Las anomalías máximas están asociadas al levante de veda en el mes de Junio como se describe anteriormente para la estacionalidad, así como se localizan algunos asociados a la temporada de recalo (octubre-febrero).

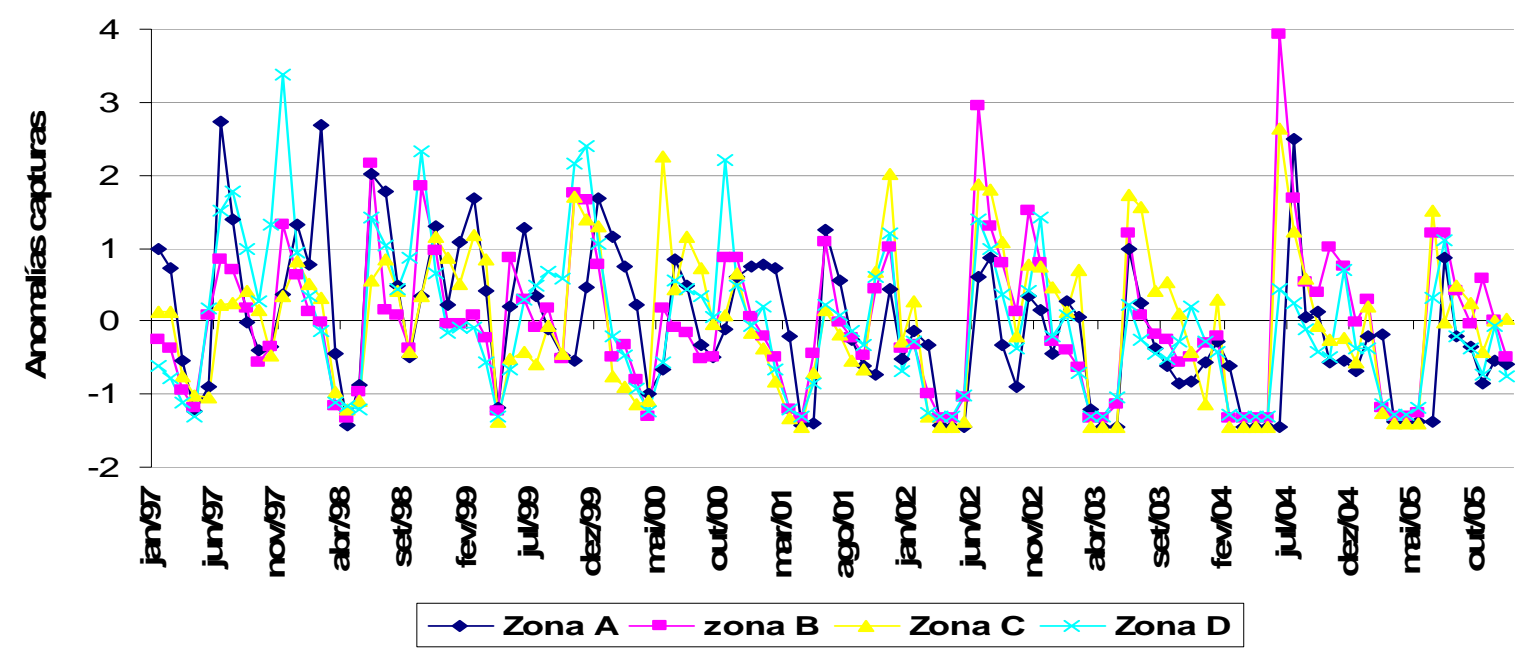

Figura 6. Anomalías de las capturas de langosta por zonas de pesca, período 1997-2004. (Zona A: Golfo Ana María Guacanayabo; Zona B: Golfo de Batabanó; Zona C: Archipiélago de las Coloradas; Zona D: Archipiélago Sabana-Camagüey).

A nivel nacional se observa una tendencia al decrecimiento de las capturas que es el reflejo de condiciones hidroclimáticas que pueden limitar el reclutamiento y afectar áreas de cría y el no cumplimiento cabal de regulaciones pesqueras o una veda insuficiente Puga 
(2005). Particularizando por zonas de pesca se observa que las amplitudes varían entre -1,5 y 2 toneladas. Siendo encontrados picos positivos de capturas en todas las zonas en junio de los años 2002 y 2004, con máximos para el Golfo de Batabanó, que fueron explicados por Piñeiro (2004) y Puga (2005), como una respuesta de las capturas al cumplimiento de las medidas regulatorias, así como por las buenas condiciones ambientales y el paso de huracanes de alta intensidad por la zona.

\subsection{Relaciones de la ATSM con las capturas de langosta}

Teniendo en cuenta que las capturas de langosta en Cuba cuentan con un período de veda, solo son correlacionados los meses donde se desarrollan las operaciones pesqueras plenamente o sea, desde el levante de veda en Junio hasta el cierre de las pesquerías en Febrero. Las correlaciones de las ATSM con los registros mensuales de capturas por área de pesca se realizan con el mismo año, el año siguiente y hasta un desfase de 5 años teniendo en cuenta las posibles edades de los animales.

Fry (1971) planteó, que la temperatura es un factor decisivo para el crecimiento de la langosta espinosa porque controla la tasa metabólica, también en Gomes (1980) se logra una predicción del pico de maduración de las langostas en el Golfo de Batabanó mediante el establecimiento de una relación entre estas y la temperatura del aire. Para esta misma área Hernández (2002) determina que existe correlación de las ATSM con las capturas de langosta con dos años de desfase y siendo más significativas para el mes de diciembre con un valor de 0,49 .

Especificando por zonas de pesca para el área de estudio seleccionada la Figura 7 muestra que para la zona A existe mayor correlación en los meses de noviembre $(0,97)$ y diciembre $(0,94)$ a los 4 y 5 años de desfase respectivamente, las menores correlaciones $(-0,07)$ se observan en media (Figura 8) para 1 año de desfase y las máximas para tres años

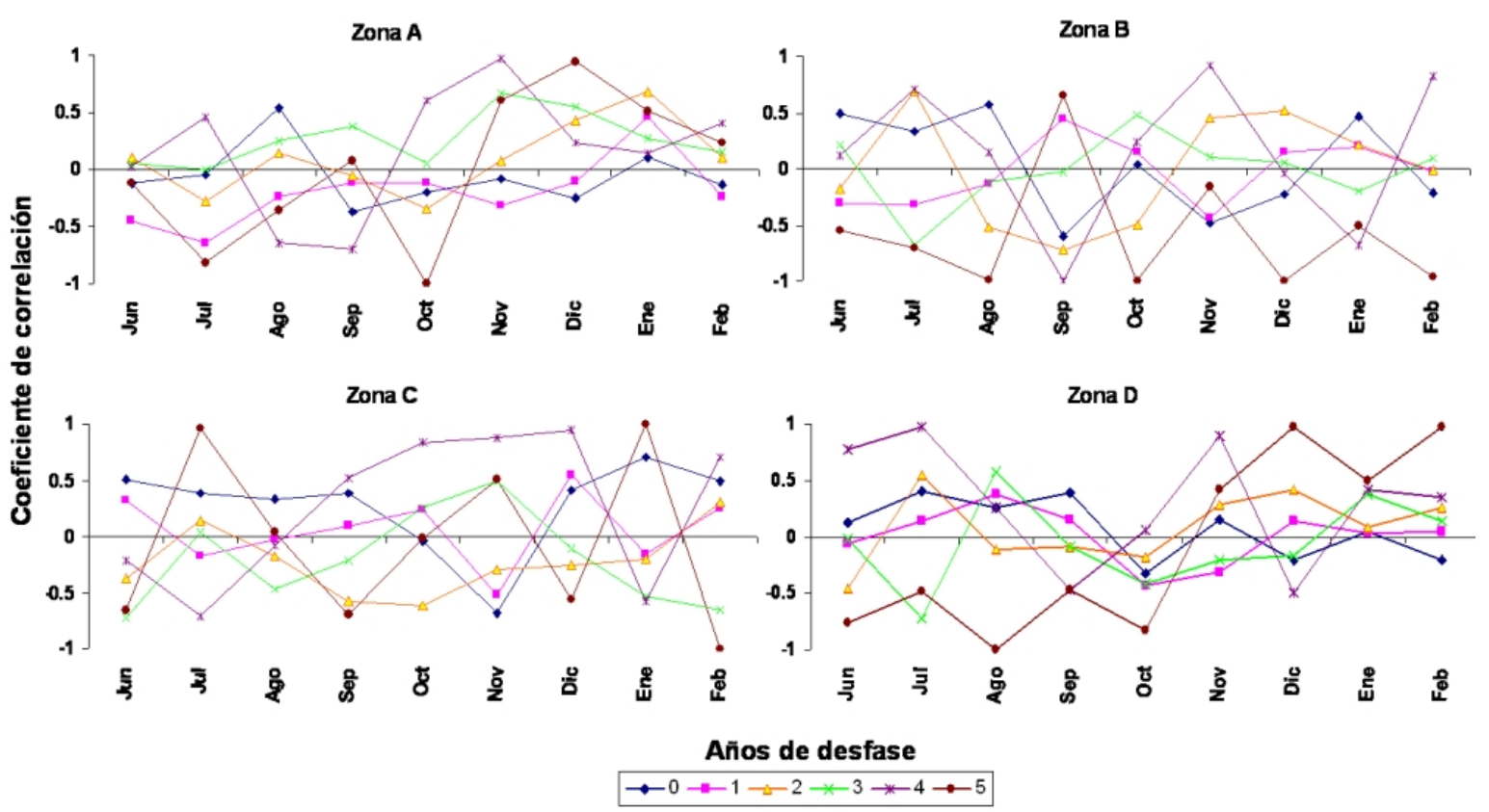

Figura 7. Coeficiente de correlación mensual entre las capturas y las ATSM por zonas de pesca con desfase temporal de 0 a 5 años.

$(0,28)$, sin embargo valor extremo de la mínima se registro en el mes de octubre $(-0,83)$ con 5 años de desfase. En la zona B se obtienen valores de correlación variables a lo largo del año (Figura 7) pero se definen máximos en noviembre $(0,90)$ y febrero $(0,80)$ con 4 años de 
desfase, también es con este desfase (Figura 8) que se obtienen las máximas correlaciones con valores de 0,48 en medias anuales y los mininos un año de desfase.

La zona C presentó un comportamiento de máximas (Figura 7) desde septiembre hasta diciembre $(0,52 ; 0,83 ; 0,88 ; 0,95$ respectivamente) a los 4 años de desfase, lógicamente es a los 4 años donde existe mayor correlación para esta área (Figura 8), mientras que fueron observados picos en Julio $(0,96)$ y Enero $(0,98)$ con 5 años de desfase. En cuanto a los mínimos el valor extremo se registró para febrero $(-0,93)$ con 5 años de desfase mientras que como promedio es a los 2 años de desfase donde es inferior la media $(0,21)$. La zona D es la que presenta menores coeficientes de correlación de las ATSM con las capturas de langosta (Figura 8) en el área, siendo observados picos de máxima (Figura 7) en Julio $(0,96)$ y Noviembre $(0,88)$ a los 4 años de desfase, por otro lado se observan otros dos picos en Diciembre y Febrero a los 5 años, siendo en este tiempo de desfase donde paradójicamente también se registra el valor extremo mínimo en Agosto (-0,99).

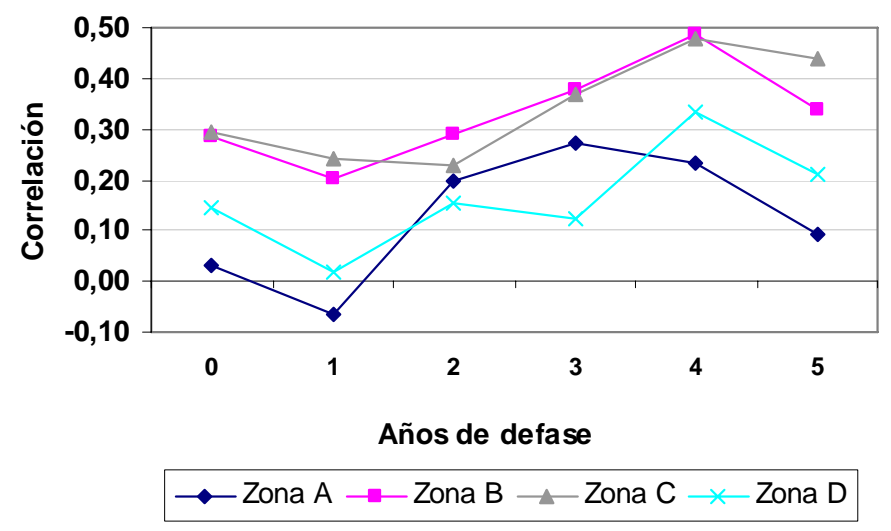

Figura 8. Coeficientes de correlación entre las ATSM y las anomalías de las capturas de langosta para las zonas de pesca. Desfasado en el tiempo de 0-5 años.

Puga (2005) esboza que la edad promedio de los animales capturados por zona de pesca varía entre 2,5 - 7 años, en dependencia de la profundidad de la zona, siendo capturados los de menor edad en la zona D y los mayores en la zona A. Este planteamiento y los coeficientes de correlación obtenidos conllevan al razonamiento que las ATSM dentro del ciclo de vida de la langosta estarían más relacionadas con la fase larval que se desarrolla en aguas oceánicas, pues en Alfonso et al. (1999) se destacan dos elementos los gradientes de temperatura superficial y profunda, los cuales son los factores de mayor peso en la dinámica de las larvas. Al respecto, señala una limitación en la distribución de las larvas de panulirus en la columna de agua relacionada con la profundidad de la termoclina y la restricción del movimiento de las larvas por sobre la isoterma de $26^{\circ} \mathrm{C}$ para las aguas cubanas.

Las mayores correlaciones se registraron para la zona occidental del país, de forma espacial puede observarse a través de las imágenes de ATSM (Figura 9) algunas variabilidades de poca amplitud siempre positivas en las temperaturas de aguas al sur-oeste (Zona B1) de la isla que podrían estar asociadas al patrón circular de movimiento de las aguas descrito por Garcia et al. (1991). A estos giros se les atribuye un alto por ciento de retención de las larvas producidas en el Sur de Cuba, conociendo que estas filosomas poseen una distribución típicamente oceánica encontrándose siempre en aguas fuera de la plataforma submarina. Al momento de nacer, las larvas son movidas hacia fuera por las corrientes de cascada que se producen en el borde del talud de la plataforma submarina. Este movimiento de salidas de larvas se ocasiona principalmente por efecto de la turbulencia del agua y gracias 
a su capacidad para realizar migraciones verticales diarias. Una vez que se ha completado el ciclo larval, los puerulos regresan auxiliados por el denominado transporte Ekman en dirección a la costa (Baisre et al., 1984).

Mientras que al norte del occidente (Zona C1) se observa durante el verano una ruptura de la corriente de lazo "Loop" descrita por Gyory et al. (2004) y en el invierno el frente térmico que esta provoca, pues según Souza (2005) grandes concentraciones de individuos de determinadas especies han sido encontrados a lo largo de frentes termales localizados, principalmente, próximos a vórtices y zonas de surgencias. Las condiciones favorables para el traslado y entrampe de larvas al sur- oeste de Cuba, no ocurre tan exitosamente para el Norte de Cuba, ya que las pocas amplitudes de las ATSM (Figura 9) y el esquema general de circulación de las aguas de Cuba muestran como la corriente de Lazo aglomera gran parte del volumen de agua que atraviesa el Estrecho de Yucatán como se describe en Garcia et al. (1991), la contracorriente cubana regresa sus aguas hacia la zona Sur de Pinar del Río, lo que podría incidir en gran proporción al regreso de las larvas de estadios finales hacia la plataforma. Por otro lado Alfonso et al. (1999) plantea que el sistema de vientos influye en que gran parte de las larvas al noreste de la isla (Zona D) se dispersen y continúen su curso hacia el norte con la corriente de la Florida, y se pierdan o se asienten en otras plataformas, lejos de las nuestras.
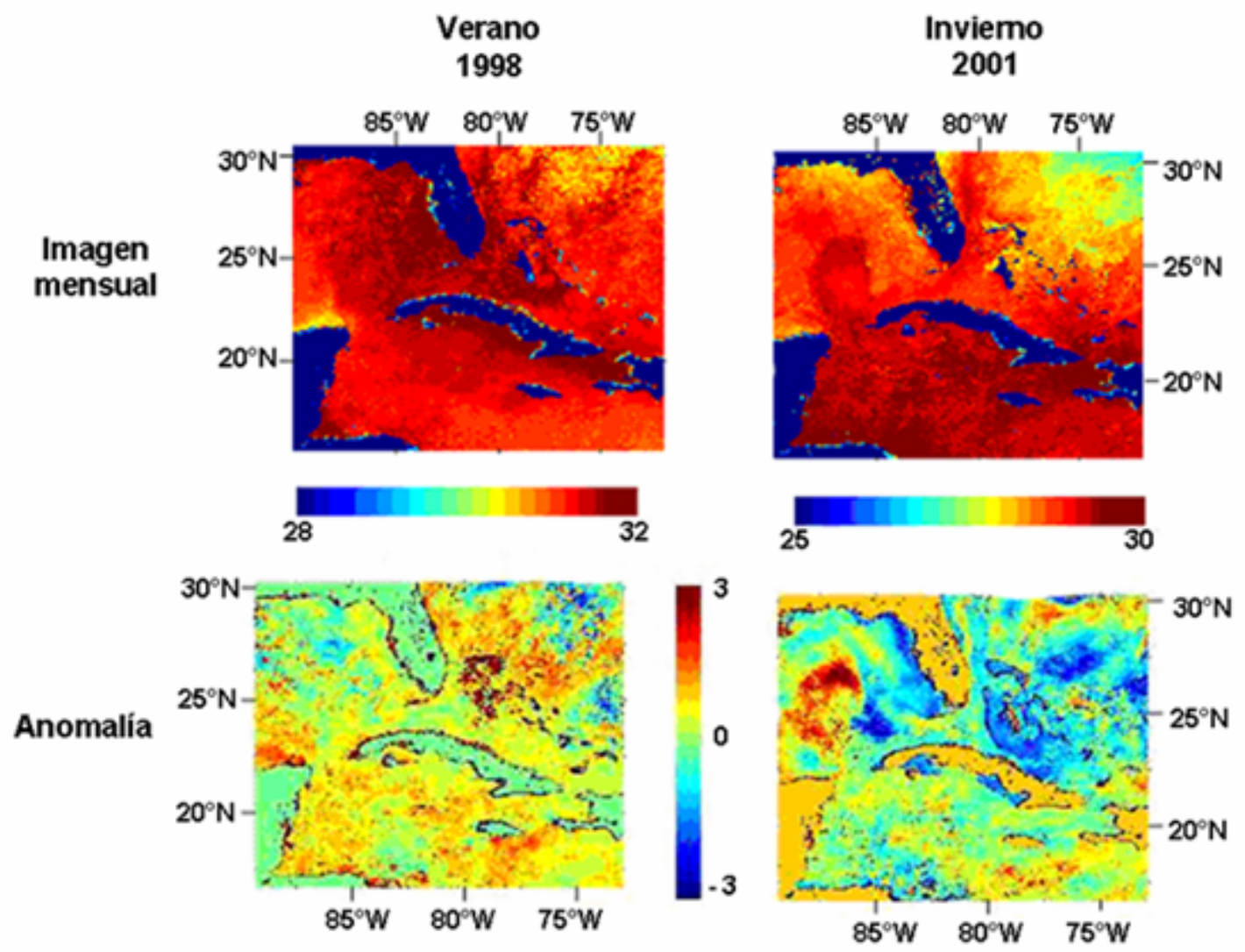

Figura 9. Imágenes AVHRR y las anomalías TSM, representativas de los máximos extremos registrados, positivos para el verano del 1998 mes de agosto, (izquierda); negativos para el invierno del 2001 mes de febrero (derecha). 


\section{CONCLUSIONES}

Se determinó una estacionalidad anual bien definida por dos patrones de la TSM, para el área, en el período invernal (Noviembre-Abril) puede apreciarse el dinamismo de las aguas a través de los frentes térmicos formados en los límites de la circulación, mientras que durante el verano (Mayo-Octubre) no se define.

Las ATSM, tienen un comportamiento similar para todas las regiones tanto de la plataforma como en las aguas adyacentes con un coeficiente de correlación de 0,98 entre estas masas de agua y los valores extremos máximos positivos para el año 1998; los máximos negativos se registran en el 2001.

Se determina muy baja correlación entre las ATSM y las capturas registradas para cada zona de pesca, variando desde - 0,1 a 0,48 ; obteniéndose las máximas correlaciones $(0,48)$ con un desfase de 4 años para la región occidental del país.

\section{RECOMENDACIONES}

Las anomalías de Temperatura Superficial del mar como variable aislada no deben explicar las fluctuaciones de la pesquería, sino que debe integrarse con los otros elementos bióticos y abióticos que actúan sobre los ecosistemas donde se desarrollan tanto las pesquerías como las fases del ciclo de vida de la especie. Por tanto, investigaciones futuras deben relacionar otras variables ambientales obtenidas a partir de sensores orbitales (ejemplo: clorofila, turbidez, vientos, coeficiente de atenuación de la luz, etc.) con las pesquerías de langosta en Cuba considerando datos espaciales y temporales de esfuerzo pesquero.

\section{REFERENCIAS}

ALFONSO, I.; FRÍAS, M. P; BAISRE, J; HERNÁNDEZ, N; PIÑEIRO R; RODRÍGUEZ DEL REY, A. Distribución y abundancia de filosómas de Panulirus Argus y su relación con los factores hidrometeoro lógico. In: SIMPOSIO PLANTOLOGÍA' 99, 6-10 sep. 1999, La Habana. Resúmenes... La Habana: [S.n.], 1999. 16p.

BAISRE, J. A. Crónica de la pesca marítima en Cuba (1935-1995): Análisis de tendencias y del potencial pesquero. In: FAO. Documento técnico de pesca, 394. Roma: FAO, 2000. 27p. ISBN 92-5-304410-1.

BAISRE, J.; CRUZ, R. The cuban spiny lobster fishery. In: PHILLIPS, B. F.; COBB, J. S.; KITTAKA, J. (Eds.). Spiny Lobster Management. Cambridge: University Press, 1994. p. 119-132.

BAISRE, J.; GARCÍA, C.; CRUZ, R. Migraciones masivas de la langosta (Panulirus argus) en la plataforma cubana. In: SIMPOSIO DE CIENCIAS DEL MAR Y VII JORNADA CIENTÍFICA DEL INSTITUTO DE OCEANOLOGÍA, 5-9 nov. 1984, La Habana. Resúmenes... La Habana, [S.n.], 1984. p 26-28.

BROWN, O. B.; BROWN, W. J.; EVANS, R. H. Calibration of advanced very high resolution radiometer infrared observations. Journal of Geophysical Research, St. Louis, v. 90, n. 6, p. 11.667-11.677, 1985.

CERDEIRA-ESTRADA, S.; MÜLLER-KARGER, F.; GALLEGOS-GARCIA, A. Variability of the sea surface temperature around Cuba. Gulf of México Science, Dauphin Island, v. 23, n. 2, p. 161-171, 2005. 
COBB, J. S.; PHILLIPS, B. F. The biology and management of lobsters. New York: Academic Press, 1980. vol. 2.

CRUZ, R.; BAISRE, J. A.; DÍAZ IGLESIAS, E.; BRITO, R.; GARCÍA, C.; CARRODEGUAS C. Atlas Biológico-Pesquero de la Langosta en el archipiélago Cubano. Revista Mar y Pesca, La Habana, 1990. 125 p.

CRUZ, R.; DE LEÓN, M. E.; PUGA, R. Prediction of commercial catches of the spiny lobster Panulirus argus in the Gulf of Batabano, Cuba. Crustaceana, Leiden, v.68, n. 2, p. 238-244, 1995.

FOOD AND AGRICULTURE ORGANIZATION (Ed.). Informe del segundo Taller sobre Manejo de las Pesquerías de la Langosta Espinosa del Área de la COPACO. La Habana, Cuba, 30 de septiembre - 4 de octubre de 2002. In: FAO Fisheries Report/FAO Informe de Pesca. No. 715. Roma, 2003. 273p Disponible en: <http://www.fao.org/ DOCREP/006/Y4931B/Y4931B00.HTM>. Acceso en julio 2006. ISSN 0429-9337.

FRY, F. E. J. The effect of environmental factors on the physiology of fish. In: HOAR, W. S.; RANDALL, D. J. (Eds.). Fish Physiology. New York: Academic, 1971. p. 1-98. vol. 6.

GARCÍA, C.; HERNÁNDEZ, B.; BAISRE, J.; CRUZ, R. Factores climáticos en las pesquerías cubanas de langosta (Panulirus argus): su relación con las migraciones masivas. Revista de Investigaciones Marinas, Valparaiso, v.12, n.1-3, p. 131-139, 1991.

GÓMEZ, J. A. Relación entre la temperatura del aire y la maduración de langostas (Panulirus argus) en la plataforma sur occidental de Cuba. Revista Cubana de Investigaciones Pesqueras, La Habana, v. 5, n. 4, p.54-61, 1980.

GYORY, J.; MARIANO, A. J.; RYAN. E. H Ocean surface currents: the cearibbean current. Miami: Cooperative Institute of Marine and Atmospheric Studies, 2004. Disponible en: <http://oceancurrents.rsmas.miami.edu/caribbean/ caribbean.html>. Acceso en junio 2006.

HERNÁNDEZ, B. Recalo 1986-1987 de la langosta (P. argus) en el Golfo de Batabanó. Revista Cubana de Investigaciones Pesqueras, La Habana, v. 15, n. 1/4, 1988.

HERNANDÉZ, B. Variabilidad interanual de las anomalías de la temperatura superficial del mar en aguas cubanas y su relación con eventos El Niño-Oscilación del Sur (ENOS).

Revista de Investigaciones Marinas, Valparaíso, v. 30, n. 2, p. 21-31, 2002.

HERNÁNDEZ, B.; GARCÍA C.; BAISRE, J. ¿Pueden los ciclones tropicales provocar migraciones masivas de langostas? Revista Cubana de Investigaciones Pesqueras, La Habana, v. 18, n. 3, p.23-25, 1995.

HERNÁNDEZ, B.; PUGA, R. Influencia del fenómeno El Niño en la región occidental de Cuba y su impacto en la pesquería de langosta (Panulirus argus) del golfo de Batabanó. Revista de Investigaciones Marinas, Valparaiso, v. 23, p.03-24, 1995. ISSN 07177178 .

INSTITUTO DE GEOGRAFÍA DE LA ACC; INSTITUTO CUBANO DE GEODESIA Y CARTOGRAFÍA (Eds.). Nuevo Atlas Nacional de Cuba. La Habana, 1989. 
MINNETT, P. J. Consequences of sea surface temperature variability on the validation and applications of satellite measurements. Journal of Geophysical Research, St. Louis, v. 96, n. C10, p. 18475-18489, 1991.

PAULY, D.; WATSON, R.; CHRISTENSEN, V. Ecological geography as framework for a transition toward responsible fishing: reykjavik conference on responsible fisheries in the marine ecosystem. Reykiavik: Abstracts book, 2001.

PEREZ-SANTOS, I. Régimen de circulación en bahías someras de la plataforma norcentral de Cuba: caso de San Juan de Los Remedios y Buenavista. 2006. Disertación (Master en Ciencias) - Universidad de Concepción, Concepción, 2006.

PIÑEIRO. R. Manejo integrado del recurso langosta en la zona costera sur de pinar del rio. 2004. 89f. Disertación (Master en Ciencias) - Centro de Investigaciones Marinas, Universidad de La Habana, La Habana, 2004.

PUGA, R.; Modelación bioeconómica y análisis de riesgo de la pesquería de langosta espinosa Panulirus argus (Latreille, 1804) en el Golfo de Batabanó, Cuba. 2005. 97f. Tesis (Doctor en Ciencias) - Centro de Investigaciones Biológicas del Noroeste, La Paz, 2005.

ROBINSON, I. S. Measuring the oceans from space, the principles and methods of satellite oceanography, Springer: praxis books in geophysical sciences. Chichestes: Praxis Publishing, 2004.

ROBINSON, I. S. Satellite Oceanography-an introduction for oceanographers and remote-sensing scientists. Chichester: Ellis Horwood, 1985.

SOUZA, R. B. Introdução à oceanografia por satélites. In: (Org.). Oceanografia por Satélites. São Paulo: Oficina de Textos, 2005. p. 15-19. vol. 1. ISBN 85-86238-48-1.

VAZQUEZ, J.; PERRY, K.; KILPATRICK, K. NOAA/NASA AVHRR Oceans Pathfinder Sea Surface Temperature Data Set: user's reference manual version 4.0. [S.l.]: JPL Publication D-14070, 1998. Disponible en: <http://podaac.jpl.nasa.gov/pub/sea_surface _temperature/avhrr/pathfinder/doc/usr_gde4_0_toc.html>. Acceso en mayo 2006.

WARRIOR, H. K. L.; CARDER, Z. P.; LEE, D. O.; CHEN. R. An improved optical model for heat and salt budget estimation for general ocean circulation models. In: OCEAN OPTICS, 16., 2002, Santa Fé. Abstracts... Arlington: Office of Naval Research, 2002. 